\title{
Release of Iron-Loaded Ferritin in Sodium Iodate-Induced Model of Age Related Macular Degeneration: An In-Vitro and In-Vivo Study
}

\author{
Ajay Ashok ${ }^{1} \mathbb{D}$, Suman Chaudhary ${ }^{1}{ }^{\mathbb{D}}$, Aaron S. Wise ${ }^{1}$, Neil A. Rana ${ }^{1}$, Dallas McDonald ${ }^{1}$, \\ Alexander E. Kritikos ${ }^{1}$, Ewald Lindner ${ }^{2}$ (D) and Neena Singh ${ }^{1, *(D)}$ \\ 1 Department of Pathology, School of Medicine, Case Western Reserve University, Cleveland, OH 44106, USA; \\ axa864@case.edu (A.A.); sxc1351@case.edu (S.C.); asw80@case.edu (A.S.W.); nar66@case.edu (N.A.R.); \\ djm259@case.edu (D.M.); aek103@case.edu (A.E.K.) \\ 2 Department of Ophthalmology, Medical University of Graz, Auenbruggerplatz 4, 8036 Graz, Austria; \\ ewald.lindner@medunigraz.at \\ * Correspondence: neena.singh@case.edu
}

check for

updates

Citation: Ashok, A.; Chaudhary, S.; Wise, A.S.; Rana, N.A.; McDonald, D.; Kritikos, A.E.; Lindner, E.; Singh, N. Release of Iron-Loaded Ferritin in Sodium Iodate-Induced Model of Age Related Macular Degeneration: An In-Vitro and In-Vivo Study. Antioxidants 2021, 10, 1253. https://doi.org/10.3390/antiox10081253

Academic Editor: Michele Marino

Received: 5 June 2021

Accepted: 30 July 2021

Published: 5 August 2021

Publisher's Note: MDPI stays neutral with regard to jurisdictional claims in published maps and institutional affiliations.

Copyright: (c) 2021 by the authors. Licensee MDPI, Basel, Switzerland. This article is an open access article distributed under the terms and conditions of the Creative Commons Attribution (CC BY) license (https:// creativecommons.org/licenses/by/ $4.0 /)$.
Abstract: In this report, we evaluated the role of iron in sodium iodate $\left(\mathrm{NaIO}_{3}\right)$-induced model of agerelated macular degeneration (AMD) in ARPE-19 cells in-vitro, and mouse models in-vivo. ARPE-19 cells, a human retinal pigmented epithelial cell line, were exposed to $10 \mathrm{mM}$ of $\mathrm{NaIO}_{3}$ for $24 \mathrm{~h}$, and the expression and localization of major iron modulating proteins was evaluated by Western blotting (WB) and immunostaining. Synthesis and maturation of cathepsin-D (cat-D), a lysosomal enzyme, was evaluated by quantitative reverse-transcriptase polymerase chain reaction (RT-qPCR) and WB respectively. For in-vivo studies, C57BL/6 mice were injected with $40 \mathrm{mg} / \mathrm{kg}$ mouse body weight of $\mathrm{NaIO}_{3}$ intraperitoneally, and their retina was evaluated after 3 weeks as above. We observed that $\mathrm{NaIO}_{3}$ induced a 10-fold increase in ferritin in ARPE-19 cells, which co-localized with LC3II, an autophagosomal marker, and LAMP-1, a lysosomal marker. A similar increase in ferritin was noted in retinal lysates and retinal sections of $\mathrm{NaIO}_{3}$-injected mice by $\mathrm{WB}$ and immunostaining. Impaired synthesis and maturation of cat-D was also noted. Accumulated ferritin was loaded with iron, and released from retinal pigmented epithelial (RPE) cells in Perls' and LAMP-1 positive vesicles. These observations suggest that $\mathrm{NaIO}_{3}$ impairs lysosomal degradation of ferritin by decreasing the transcription and maturation of cat-D in RPE-19 cells. Iron-loaded ferritin accumulates in lysosomes and is released in lysosome membrane-enclosed vesicles in the extracellular milieu. Accumulation of ferritin in RPE-19 cells and fusion of ferritin-containing vesicles with adjacent photoreceptor cells is likely to create iron overload, compromising their viability. Moreover, reduced activity of cat-D is likely to promote the accumulation of other cellular debris in lysosomal vesicles, contributing to AMD-like pathology.

Keywords: ferritin; exosomes; age-related macular degeneration; lysosomes; sodium iodate

\section{Introduction}

Retinal iron accumulation and iron-mediated oxidative stress are considered risk factors for age-related macular degeneration (AMD), a leading cause of blindness in developed countries [1,2]. Several etiological factors contribute to the development of AMD, including genetic, metabolic, and environmental. The multifactorial nature of this disorder has been a significant challenge in developing effective therapeutic options. Dysfunction of the retinal pigment epithelial (RPE) cell layer is a consistent observation and is clinically identified with the accumulation of extracellular amorphous material, known as drusen, between the RPE cell layer and inner layer of the Bruch's membrane. Accumulation of phagocytosed material including break-down products of photoreceptor outer segments (POS) results in the loss of metabolic support and eventual death of RPE and photoreceptor cells, resulting in irreversible vision loss [3-8]. 
RPE cells are a monolayer of specialized epithelial cells that form the outer bloodretinal barrier (BRB) on their basolateral side and interact closely with the photoreceptor cell layer on the apical side $[9,10]$. The BRB regulates the exchange of nutrients and metabolites between peripheral blood and the retina, and interaction with photoreceptors facilitates the essential function of phagocytosis and turnover of POS. Each day, $10 \%$ of the total volume of photoreceptor cells is phagocytosed, and roughly the same amount is regenerated. Since RPE cells are post-mitotic, disposal of phagocytosed material is necessary to avoid waste build-up, including an efficient autophagosomal-lysosomal machinery. In fact, RPE is the most active phagocytic cell in the body, and perturbation of this function results in retinal disease, including AMD [6,11].

Features typical of AMD have been reproduced by the accumulation of iron in the human retina and in experimental models [1,12]. In hemochromatosis and aceruloplasminemia, hereditary human disorders associated with systemic iron overload, iron collects in the retina despite an intact BRB, resulting in AMD-like pathology [1,13]. Likewise, administration of intravenous iron for refractory anemias leads to retinal iron accumulation, and is a risk factor for AMD [14]. The retina of aged individuals has significantly more iron than young adults [15], supporting a significant role of iron in AMD pathogenesis. In experimental mouse models, absence of ceruloplasmin and hephaestin, ferroxidases necessary for iron export, results in retinal iron overload and AMD-like pathology [2,16], reinforcing the involvement of iron. In cultured ARPE-19 cells, exposure to iron decreases their phagocytic activity and lysosomal function $[17,18]$, a characteristic typical of AMD.

Sodium iodate $\left(\mathrm{NaIO}_{3}\right)$, an oxidizing agent, has been used extensively to replicate human AMD in cell and animal models. Toxicity by $\mathrm{NaIO}_{3}$ is specific to RPE cells, and low doses cause patchy loss of tight junctions, disrupt outer and inner photoreceptor segments, and cause accumulation of degradation products of POS typical of AMD [19]. The mechanisms underlying these changes have been explored extensively, with each report emphasizing the significance of a specific biochemical pathway [20-25]. Interestingly, partial reversal of $\mathrm{NaIO}_{3}$-induced AMD in animal models by the iron chelator deferiprone [26] suggests a significant role of iron in AMD pathogenesis. In this report, we evaluated the role of iron in $\mathrm{NaIO}_{3}$-induced AMD in C57BL/ 6 mice and human ARPE-19 cells.

\section{Methods}

\subsection{Ethics Statement}

All animal experiments were approved by the Institutional Animal Care and Use Committee at the School of Medicine, Case Western Reserve University (ethical protocol number: 2015-0027), and were conducted in accordance with the guidelines of the Association for Research in Vision and Ophthalmology on the use of animals in research. Animals were housed in the Association of Assessment and Accreditation of Laboratory Animal Care International (AAALAC)-approved Animal Resource Center (ARC) at Case Western Reserve University School of Medicine. All methods adhered to the ARVO Statement for the Use of Animals in Ophthalmic and Vision Research.

\subsection{Antibodies and Chemicals}

The list of antibodies used in the study are provided in Supplementary Table S1. Sodium iodate $\left(\mathrm{NaIO}_{3}\right)$ and all other chemicals were obtained from Sigma Aldrich, Milwaukee, WI, USA (S4007-100G). Cathepsin-D siRNA was obtained from Santa Cruz, Dallas, TX, USA (sc-29239). Lipofectamine RNAiMax was from Invitrogen, (Fulfilled by Supply Center, Cleveland, OH, USA).

\subsection{Animals}

C57BL/6J mice (5 per group) were injected intraperitoneally with $\mathrm{NaIO}_{3}(40 \mathrm{mg} / \mathrm{kg}$ mouse body weight) or equal volume of saline, and sacrificed after 3 weeks. Retinal lysates were processed for Western blotting (WB), and thin sections from fixed tissue were evaluated by immunohistochemistry. Retinal tissue and a piece of brain tissue from the 
frontal cortex of 5 mice from each experimental group were pooled, and an equal amount of protein was evaluated for ferritin expression by WB.

\subsection{Cell Culture}

Human retinal pigmented epithelial cell line (ARPE-19; ATCC ${ }^{\circledR}$ CRL-2302 ${ }^{\mathrm{TM}}$ ) was used from passage 4 to 20 . The phenotype of these cells was confirmed before use by probing cell lysates for RPE 65 by WB, a marker for RPE cells [27]. Cultures were maintained in Dulbecco's Modified Eagle Medium/Nutrient Mixture F-12 (DMEM/F12) supplemented with $10 \%$ fetal bovine serum (FBS), $100 \mathrm{U} / \mathrm{mL}$ penicillin, and $100 \mu \mathrm{g} / \mathrm{mL}$ streptomycin. The medium was changed every 2 days, and sub-confluent cultures in 1\% FBS were treated with $10 \mathrm{mM} \mathrm{NaIO}_{3}$ for $24 \mathrm{~h}$ before processing for WB and immunostaining. To silence cat-D, the cells were transfected with cat-D-specific or the corresponding scrambled siRNA using Lipofectamine RNAiMax as per manufacturer's instructions. Desired downregulation of cat-D was confirmed by WB.

\subsection{Sodium Dodecyl Sulfate Polyacrylamide Gel Electrophoresis (SDS-PAGE) and Western Blotting}

Protein lysates were fractionated on SDS-PAGE and analyzed by WB as described earlier [28,29]. Proteins of interest were detected in transferred lysates with specific antibodies followed by species-specific horseradish peroxidase (HRP)-conjugated secondary antibody (Supplementary Table S1). Specific bands were visualized on an X-ray film with enhanced chemiluminescence. Full blots and their details are provided in Supplementary Figure S1.

\subsection{Quantitative Reverse-Transcriptase Polymerase Chain Reaction (RT-qPCR)}

Total RNA was isolated from cells using RNAqueous ${ }^{\circledR}$-Micro Kit (AM1931, Invitrogen (Fulfilled by Supply Center, Cleveland, OH, USA) according to manufacturer's instructions, and PCR reactions were primed with BrightGreen 2X QPCR MasterMix (MasterMix-R) (Applied Biological Materials Inc, Ferndale, WA, USA). The mRNA of interest was amplified using the following primers: Hu cat-D-F: CTGCACAAGTTCACGTCCAT-3', Hu cat-D-R: TTCTGCTGCATCAGGTTGTC-3' (Accession No.: NM_001909.5). Hu GAPDHF: GAGTCAACGGATTTGGTCGT-3' ${ }^{\prime}$, Hu GAPDH-R: GGTGCCATGGAATTTGCCAT- ${ }^{\prime}$ (Accession No.: NM_001289745.3). All primers were obtained from Integrated DNA Technologies, Coralville, IA, USA.

\subsection{Immunostaining}

Immunostaining of fixed cells and retinal tissue sections was performed essentially as described [30,31]. Following treatments, ARPE-19 cells were washed with $1 \times$ PBS, fixed using $4 \%$ paraformaldehyde, blocked using $2 \%$ bovine serum albumin (BSA) and co-immunostained. The cells were incubated with antibodies against LC3II (produced in rabbit) and ferritin (produced in goat) and were detected using anti-rabbit secondary antibody conjugated with Alexa Fluor 546 (red) and anti-goat secondary antibody conjugated with Alexa Fluor 488 (green), respectively. Co-immunostained ARPE-19 cells were incubated with antibodies against LAMP-1 (produced in rabbit) and ferritin (produced in goat) and were detected using anti-rabbit secondary antibody conjugated with Alexa Fluor 546 (red) and anti-goat secondary antibody conjugated with Alexa Fluor 488 (green), respectively. Controls were treated with no primary antibodies but reacted with both secondary antibodies (Supplementary Figure S2). Staining of retinal tissue sections was performed similarly, and serial sections were used as controls for staining with secondary antibody only (Supplementary Figure S3).

Hoechst was used to stain the nuclei in all immunostaining experiments. Stained samples were imaged with Leica inverted microscope (DMi8). Each experiment was repeated three times, and a representative image from 10 different fields is shown. 


\subsection{Perls' Staining}

Perls' staining was performed as described earlier [32]. Cells and tissue sections were rinsed, let to react with a mixture of ferrocyanide- $\mathrm{HCl}$ for $10 \mathrm{~min}$, and counter-stained with filtered neutral red stain for $1 \mathrm{~min}$. Stained samples were rapidly dehydrated in absolute alcohol and mounted for imaging with an upright microscope (Leica Microscope Imaging System; Leica, Wetzlar, Germany). Each experiment was repeated 3 times, and a representative image from 10 different fields is shown.

\subsection{Statistical Analysis}

Densitometry of images was performed with UN-SCAN-IT gels (version 6.1) software (Silk Scientific, Orem, UT, USA) and Image J software (Version: 1.53K, National Institutes of Health, Bethesda, MD, USA). All data were statistically analyzed by GraphPad Prism software (Version 5.0, GraphPad Software Inc., San Diego, CA, USA) and are shown as mean \pm SEM. Significant differences between control and experimental samples were determined by the Student's unpaired $t$-test or Two-way ANOVA. Differences were considered statistically significant at $p \leq 0.05$.

\section{Results}

\subsection{Ferritin Is Upregulated by Sodium Iodate in ARPE-19 Cells}

To assess the role of iron in $\mathrm{NaIO}_{3}$-mediated AMD-like changes in ARPE-19 cells, three independent sets of sub-confluent cultures were exposed to $10 \mathrm{mM} \mathrm{NaIO}_{3}$ for $24 \mathrm{~h}$, and the expression of major iron modulating proteins ferritin, transferrin receptor (TfR), hepcidin, and ferroportin (Fpn) was evaluated by WB. Probing for ferritin revealed significantly increased levels in $\mathrm{NaIO}_{3}$-treated relative to vehicle-treated controls in all three sets (Figure 1A, lanes 2, 4, and 6 vs. 1, 3, and 5; Figure 1B). Surprisingly, re-probing for transferrin receptor (TfR) showed no change in its levels despite the increased levels of ferritin (Figure 1A, lanes 2, 4, and 6 vs. 1, 3, and 5; Figure 1B). Normally, an increase in intracellular iron is expected to downregulate the TfR, an iron uptake protein, to block additional uptake of iron.

Another consequence of intracellular accumulation of iron is decreased expression of hepcidin, the master regulator of iron homeostasis, thereby sparing Fpn and increasing iron export. ARPE-19 cells are known to synthesize hepcidin [33] and regulate their iron content and its transport from the peripheral circulation to the retina by modulating the expression of Fpn. Probing of $\mathrm{NaIO}_{3}$-treated ARPE-19 cell lysates for pro-hepcidin, a precursor of hepcidin most prominent in cell lysates, showed no change in its levels relative to vehicle treated controls (Figure 1C, lanes 2, 4, and 6 vs. 1, 3, and 5; Figure 1D). Likewise, there was little change in Fpn (Figure 1C, lanes 2, 4, and 6 vs. 1, 3, and 5; Figure 1D). These observations suggest either of two possibilities: upregulation of ferritin is unrelated to iron accumulation, or the accumulated iron is sequestered in ferritin and unable to alter the intracellular labile iron pool (LIP).

\subsection{Ferritin Co-Localizes with the Autophagosomal Marker LC3II}

Ferritin stores iron in the relatively non-toxic, ferric form to protect cells from the relatively toxic ferrous iron and requires degradation for the release of iron when necessary. This is mediated by nuclear receptor coactivator 4 (NCOA4), an autophagy receptor which delivers iron-loaded ferritin to autophagosomes. These fuse with lysosomes, where ferritin is degraded mainly by cathepsin-D (cat-D), a lysosomal enzyme [34]. The iron released from ferritin is transported to the cytosol to replenish the LIP for metabolic purposes. Since the LIP of $\mathrm{NaIO}_{3}$-treated cells does not appear to change, it is possible that either the cells lack NCOA4 and are unable to deliver ferritin to autophagosomes, or the degradation of ferritin in lysosomes is impaired, resulting in its accumulation. 
A

ARPE-19 cells

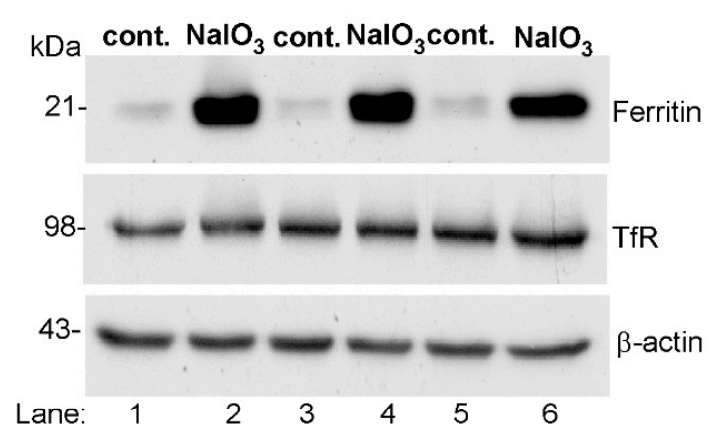

C

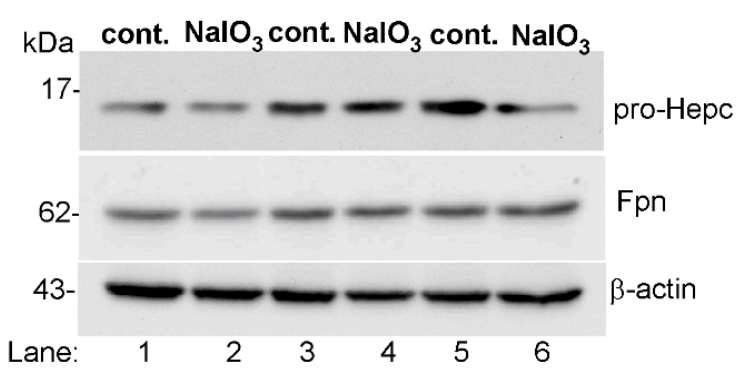

B

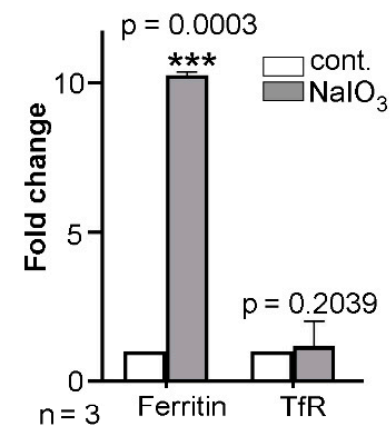

D

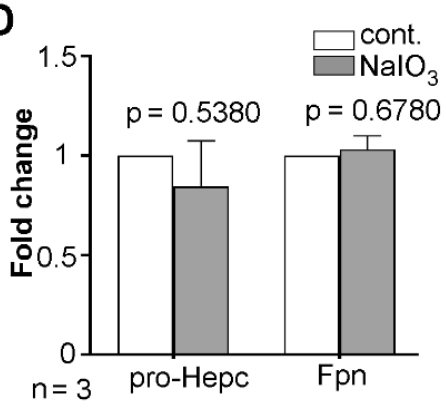

Figure 1. $\mathrm{NaIO}_{3}$ upregulates ferritin in ARPE-19 cells without altering other iron modulating proteins. (A) Probing of lysates from ARPE-19 cells exposed to $10 \mathrm{mM} \mathrm{NaIO}_{3}$ for $24 \mathrm{~h}$ for ferritin revealed significant upregulation relative to vehicle treated controls (lanes 2, 4, 6 vs. 1, 3, 5). Re-probing of the same membrane for transferrin receptor (TfR) showed no significant change in their levels between the experimental and control groups (lanes 2, 4, 6 vs. 1, 3, 5). (B) Densitometry after normalization with $\beta$-actin showed a 10 -fold increase in ferritin and minimal change in TfR by $\mathrm{NaIO}_{3}$ treatment relative to controls. (C) Probing of lysates from a similar experimental setup for prohepcidin and Fpn showed no significant change in their levels by $\mathrm{NaIO}_{3}$-treatment relative to controls (lanes $2,4,6$ vs. 1, 3,5). (D) Densitometry after normalization with $\beta$-actin shows non-significant changes in the levels of pro-hepcidin and Fpn between experimental and control samples. Full blots and their details are provided in Supplementary Figure S1. Values are means \pm SEM of the indicated n. ${ }^{* * *} p \leq 0.001$.

To evaluate this possibility, we assessed levels of NCOA4 and LC3II, the latter a marker of autophagosomes. Thus, lysates prepared from ARPE-19 cells treated with $\mathrm{NaIO}_{3}$ or vehicle for $24 \mathrm{~h}$ were processed for WB and probed for NCOA4. No difference was noted in the levels of NCOA4 in two independent samples of $\mathrm{NaIO}_{3}$-treated cells relative to controls (Figure 2A, lanes 2 vs. 1; Figure 2B). A similar evaluation of LC3II, an autophagosomal marker, showed a significant increase in expression in $\mathrm{NaIO}_{3}$-treated cells relative to controls (Figure 2C, lanes 2 and 4 vs. 1 and 3; Figure 2D), suggesting efficient formation and maturation of autophagosomes [35]. Co-immunostaining of fixed, permeabilized cells for ferritin and LC3II showed co-localization in perinuclear autophagosomes, which were more prominent in $\mathrm{NaIO}_{3}$-treated cells relative to controls (Figure 2E, panel 6 vs. 3). 


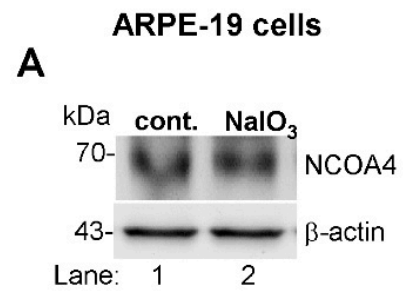

C

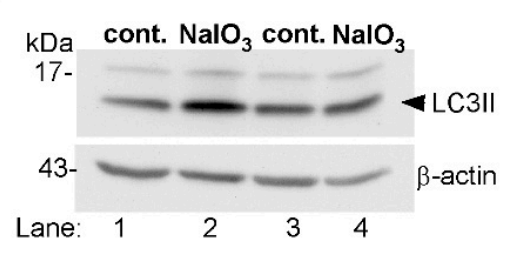

B

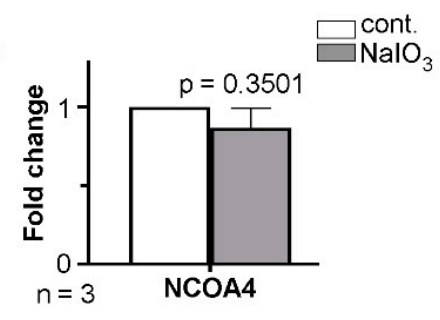

D

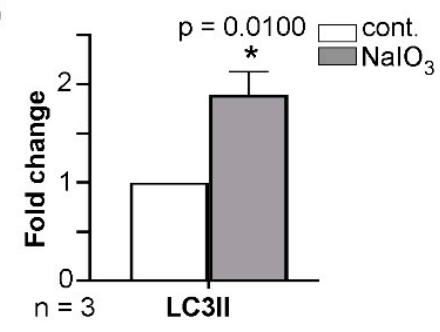

E

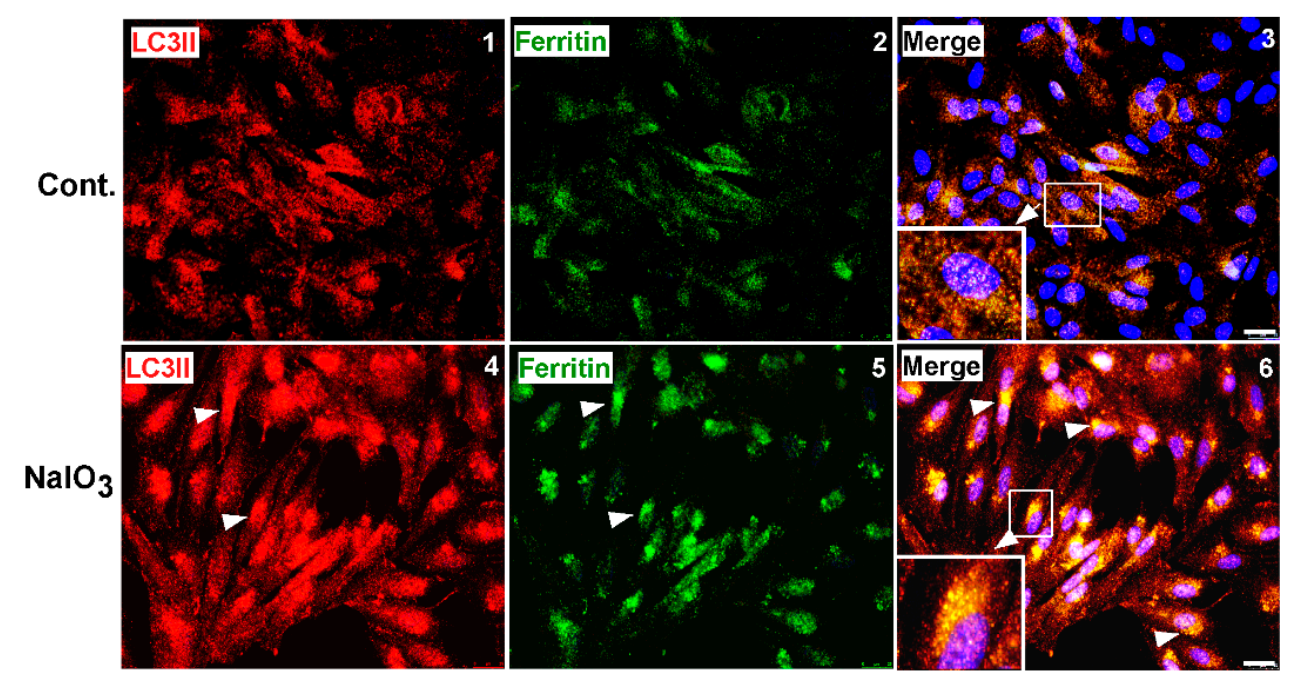

Figure 2. Ferritin accumulates in autophagosomes in $\mathrm{NaIO}_{3}$-treated cells. (A) Probing of lysates from $\mathrm{NaIO}_{3}$ treated and control cells as above for nuclear receptor coactivator 4 (NCOA4) showed no difference in expression between the experimental and control groups (lane 2 vs. 1). (B) Densitometry after normalization with $\beta$-actin showed no significant change in the levels of $\mathrm{NCOA} 4$ in $\mathrm{NaIO}_{3}$ treated cells relative to controls. (C) Probing of lysates from a similar experimental set-up for LC3II showed increased expression in $\mathrm{NaIO}_{3}$-treated cells relative to controls (lanes 2, 4 vs. 1, 3). (D) Densitometry after normalization with $\beta$-actin showed a 2-fold increase in LC3II in $\mathrm{NaIO}_{3}$-treated cells relative to controls. Full blots and their details are provided in Supplementary Figure S1. Values are means \pm SEM of the indicated $n$. ${ }^{*} p \leq 0.05$. (E) Co-immunostaining of ARPE-19 cells with goat anti-ferritin and rabbit anti-LC3II followed by species-specific Alexa Fluor 488 (green)- and Alexa Fluor 546 (red)-conjugated secondary antibodies showed increased co-localization (white arrows) of the two proteins in $\mathrm{NaIO}_{3}$-treated cells relative to untreated controls (panel 6 vs. 3). Cells treated with only secondary antibodies showed no reaction (Supplementary Figure S2). Scale bar: $25 \mu \mathrm{m}$.

Together, these results suggest that ferritin is delivered efficiently to LC3II-positive autophagosomes for subsequent fusion and degradation in lysosomes. 


\subsection{Ferritin Accumulates in Lysosomes and Is Released in LAMP-1 Positive Vesicles}

To evaluate whether autophagosomes fuse with lysosomes and deliver iron-loaded ferritin for degradation, $\mathrm{NaIO}_{3}$ - and vehicle-treated cells were fixed and co-immunostained for ferritin and the lysosomal membrane protein LAMP-1. Surprisingly, several vesicular structures positive for ferritin and LAMP-1 were detected in the intercellular space (Figure 3, panels 7,8 ). In some cells, ferritin was detected intracellularly in LAMP-1 positive lysosomes (Figure 3, panels 7, 8, arrow). Similar structures, though significantly less in number and lacking in ferritin, were detected in vehicle-treated controls (Figure 3, panels 3, 4).

\section{ARPE-19 cells}

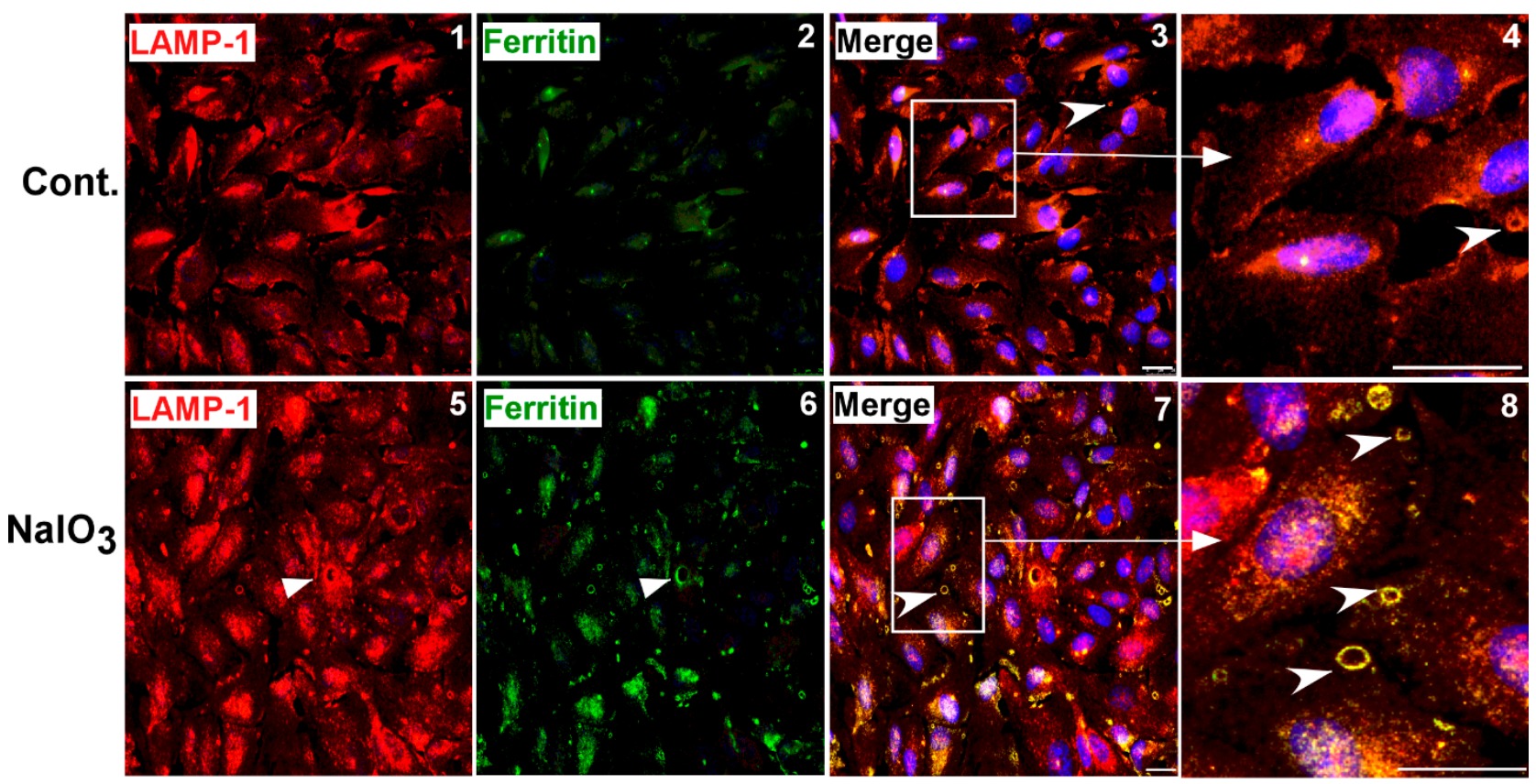

Figure 3. $\mathrm{NaIO}_{3}$ induces release of ferritin in lysosomal membrane-enclosed vesicles. Co-immunostaining of ARPE-19 cells with goat anti-ferritin and rabbit anti-LAMP-1 antibodies followed by species-specific secondary antibodies conjugated with Alexa Fluor 546 (red) and Alexa Fluor 488 (green) showed co-localization in intracellular (panels 7, 8, arrowhead) and extracellular (panels 7, 8 vs. panels 3, 4, arrowhead) vesicles in $\mathrm{NaIO}_{3}$-treated cells relative to controls. Extracellular vesicles positive for LAMP-1 were also seen in vehicle-treated controls (panels 3, 4, arrowhead). Cells treated with only secondary antibodies showed no reaction (Supplementary Figure S2). Experiments shown in Figures 2E and 3 were conducted simultaneously to maintain scientific rigor and had the same controls. Scale bar: $25 \mu \mathrm{m}$.

The release of ferritin in lysosomal membrane-enclosed vesicles suggested impaired degradation and exocytosis of accumulated ferritin. To evaluate whether cat- $\mathrm{D}$, an aspartic endo-protease responsible for the turnover of a variety of substrates including ferritin, is responsible [36,37], synthesis of cat-D was evaluated by quantitative reverse-transcriptase polymerase chain reaction (RT-qPCR). Total mRNA was isolated from triplicate cultures of $\mathrm{NaIO}_{3}$ - and vehicle-treated cells and amplified using cat-D-specific primers. A significant transcriptional downregulation of cat-D was observed in $\mathrm{NaIO}_{3}$-treated cells relative to controls (Figure 4A). Subsequent evaluation of two independent samples by WB revealed significantly reduced levels of pro-cat-D, and additionally, decreased maturation of procat-D to its mature form (Figure 4B, lanes 2 and 4 vs. 1 and 3; Figure 4C). This finding was further validated by estimating the ratio of mature to pro-cat-D using the immunoblotting results. The ratio of the intensities clearly indicated a diminished maturation of cat-D from its pro form in $\mathrm{NaIO}_{3}$-treated cells relative to controls (Figure 4D). To further confirm that cat-D downregulation inhibited ferritin turnover, ARPE-19 cells were transfected with cat-D-specific siRNA and the lysates were let to immunoreact with ferritin. Successful downregulation of cat-D resulted in increased accumulation of ferritin relative to scrambled 
siRNA-treated controls (Figure 4E, lanes 2 vs. 1; Figure 4F), suggesting ferritin to be one of the substrates processed by cat-D in these cells.

A

ARPE-19 cells

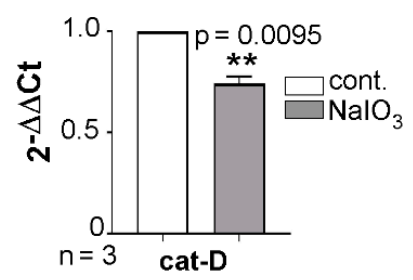

C

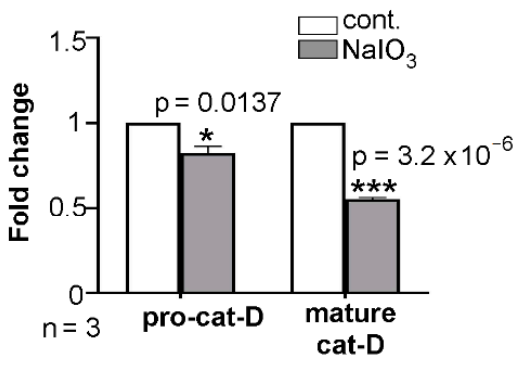

E

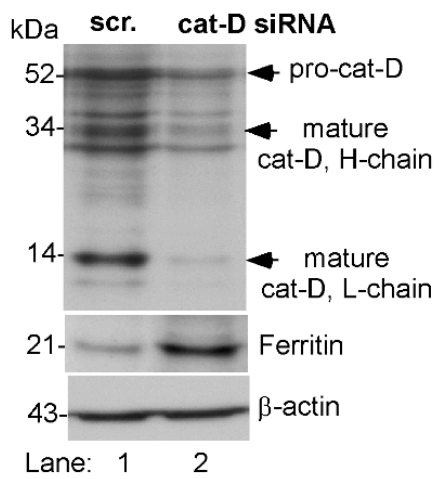

B

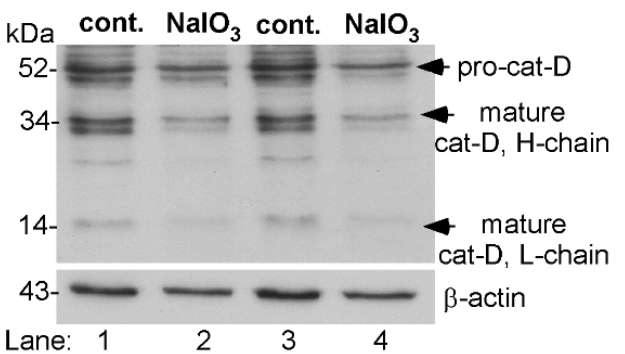

D

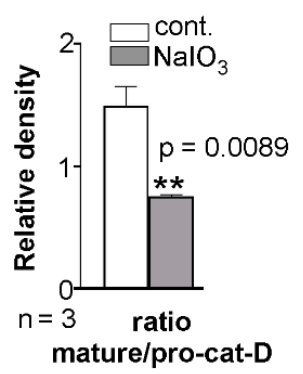

F

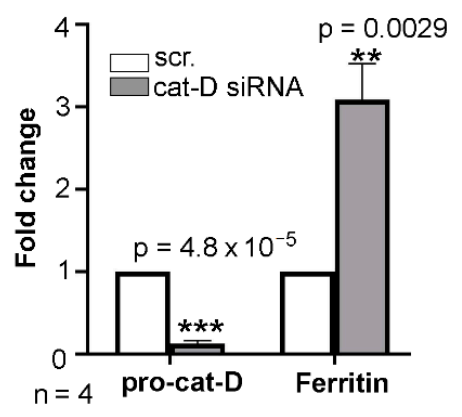

Figure 4. Synthesis and maturation of cathepsin-D is compromised by $\mathrm{NaIO}_{3}$. (A) Quantitative RT-qPCR for cat-D showed 0.75-fold downregulation in lysates from $\mathrm{NaIO}_{3}$-treated ARPE-19 cells relative to controls. Human GAPDH was amplified in parallel. (B) Probing of $\mathrm{NaIO}_{3}$-treated cell lysates for cat-D showed decreased expression of pro-cat-D and its mature form relative to controls (lanes 2,4 vs. 1, 3). (C) Densitometry after normalization with $\beta$-actin showed 0.7 - and 0.5 -fold decreases in the levels of pro-cat-D and mature cat-D in $\mathrm{NaIO}_{3}$-treated samples relative to the controls. (D) The densitometry ratio of mature cat-D relative to pro-cat-D was significantly lower in $\mathrm{NaIO}_{3}$-treated cell lysates relative to control. (E) Probing of ARPE-19 cell lysates for cat-D showed the expected reactivity of the pro-cat-D form at $52 \mathrm{kDa}$ in control cells transfected with scrambled siRNA, and minimal reaction in cells exposed to cat-D siRNA (lane 2 vs. 1). This further led to lowered levels of mature cat-D levels in cat-D siRNA-treated cell lysates. Probing for ferritin showed significant upregulation in the absence of cat-D relative to control (lanes 2 vs. 1). (F) Quantification by densitometry after normalization with $\beta$-actin showed 2.7-fold upregulation of ferritin due to downregulation of cat-D. Full blots and their details are provided in Supplementary Figure S1. Values are means \pm SEM of the indicated $n .{ }^{*} p \leq 0.05 ;{ }^{* *} p \leq 0.01 ;{ }^{* * *} p \leq 0.001$. 


\subsection{Ferritin Accumulates in the Retina of Sodium-Iodate-Injected Mice}

The in-vitro findings in ARPE-19 cells were further confirmed in mouse models. Wildtype C57BL/6 mice were given a single intraperitoneal injection of $\mathrm{NaIO}_{3}(40 \mathrm{mg} / \mathrm{kg}$ mouse body weight), and evaluated after 3 weeks. Controls received equal volume of saline. Both the retinal tissue and a piece of brain tissue from the frontal cortex of five mice were pooled, and an equal amount of protein was evaluated for ferritin levels by WB. As in ARPE-19 cells, a significant increase in ferritin was observed in retinal samples from $\mathrm{NaIO}_{3}$-treated mice relative to controls (Figure 5A, lane 2 vs. 1). No change was observed in the brain tissue of the same mice (Figure 5A, lane 4 vs. 3), confirming previous reports that $\mathrm{NaIO}_{3}$ affects the retina specifically.

Hematoxylin and Eosin (H\&E) staining of fixed retinal sections from $\mathrm{NaIO}_{3}$ and vehicle-treated controls showed well-defined retinal layers in vehicle-treated controls (Figure 5B, panel 1). The RPE and photoreceptor cell layer were uniform and well-defined as expected (Figure $5 \mathrm{~B}$, panel 2). In retinal sections from $\mathrm{NaIO}_{3}$-treated mice, the RPE cell layer was distorted, and so was the photoreceptor cell layer (Figure 5B, panels 3 and 4, white arrows) [22]. Immunostaining for ferritin showed a reaction in RPE cells and a prominent signal in photoreceptor outer segments (Figure 5B, panel 5, marked with *). In $\mathrm{NaIO}_{3}$-treated sections, a prominent reaction for ferritin was noted in the RPE cell layer and the photoreceptors (Figure 5B, panel 6, marked with *).

\subsection{Accumulated Ferritin Is Loaded with Iron}

To evaluate whether the accumulated ferritin is loaded with iron, ARPE-19 cells treated with $\mathrm{NaIO}_{3}$ or vehicle were let to react with the Perls' reagent, and the nuclei counterstained with neutral red. Several blue dots indicating positive reaction with ferric iron were detected in the extracellular space and intracellularly in $\mathrm{NaIO}_{3}$-treated cells (Figure 6A, panels 3 and 4). A rare blue dot was also detected in control cells treated with vehicle (Figure 6A, panels 1 and 2). A similar evaluation of retinal sections from $\mathrm{NaIO}_{3}$-treated mice showed Perls' positive vesicles in the space between the RPE and photoreceptor cell layer (Figure 6B, panels 3 and 4 ). No reaction was detected in vehicletreated samples (Figure 6B, panels 1 and 2).

Together, these observations suggest that $\mathrm{NaIO}_{3}$-induced toxicity is mediated by the accumulation of iron-loaded ferritin in lysosomes and its release in the surrounding tissue in membrane-enclosed vesicles. 

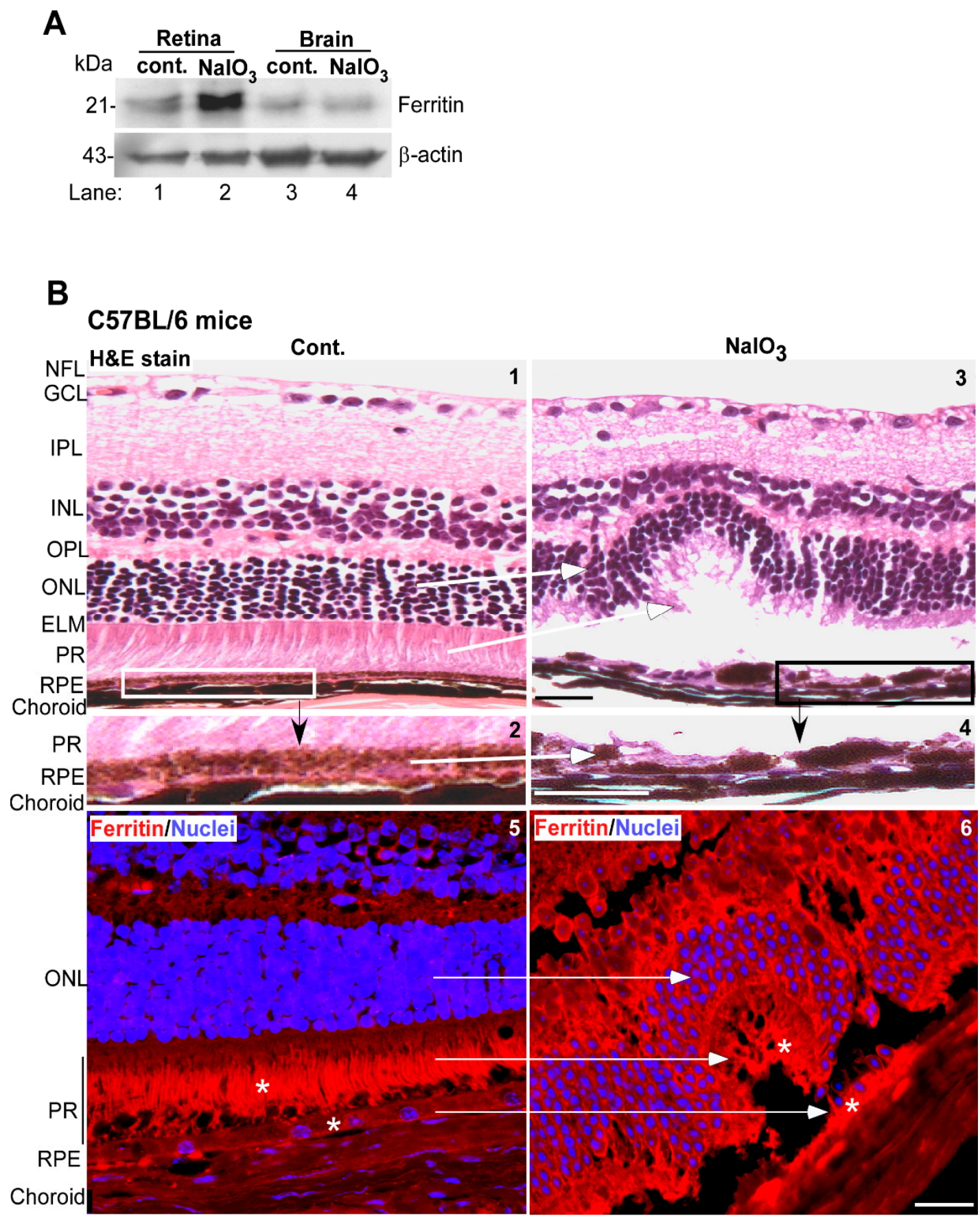

Figure 5. $\mathrm{NaIO}_{3}$ upregulates ferritin and disrupts retinal cell layers in mouse models. (A) Probing of retinal and brain lysates from $\mathrm{NaIO}_{3}$ and control mice for ferritin showed significantly higher levels in retinal samples (lane 2 vs. 1) relative to controls. Brain samples from the same mice showed a similar level of ferritin (lane 4 vs. 3). (Tissue from 5 mice was pooled for this experiment). The membranes were re-probed for $\beta$-actin as a loading control. Full blots and their details are provided in Supplementary Figure S1. (B) Hematoxylin and Eosin (H\&E) staining of mouse retina showed well-defined layers in control mice (panel 1). The boxed area is enlarged in panel 2. Mice administered $\mathrm{NaIO}_{3}$ showed disruption of the RPE and photoreceptor cell layers (panel 3). Scale bar: $25 \mu \mathrm{m}$. The boxed area is enlarged in panel 4 . Scale bar: $25 \mu \mathrm{m}$. Immunoreaction for ferritin showed increased expression in the RPE and photoreceptor cell layers of $\mathrm{NaIO}_{3}$-treated mice relative to controls (panel 6 vs. 5, marked by *). Scale bar: $25 \mu \mathrm{m}$. A serial section treated with rabbit IgG and Alexa Fluor 546-conjugated secondary antibody (red) showed no reaction (Supplementary Figure S3). RPE: retinal pigment epithelium; PR: photoreceptors; ELM: external limiting membrane; ONL: outer nuclear layer; OPL: outer plexiform layer, INL: inner nuclear layer, IPL: inner plexiform layer, GCL: ganglion cell layer; NFL: nerve fiber layer. 


\section{A ARPE-19}

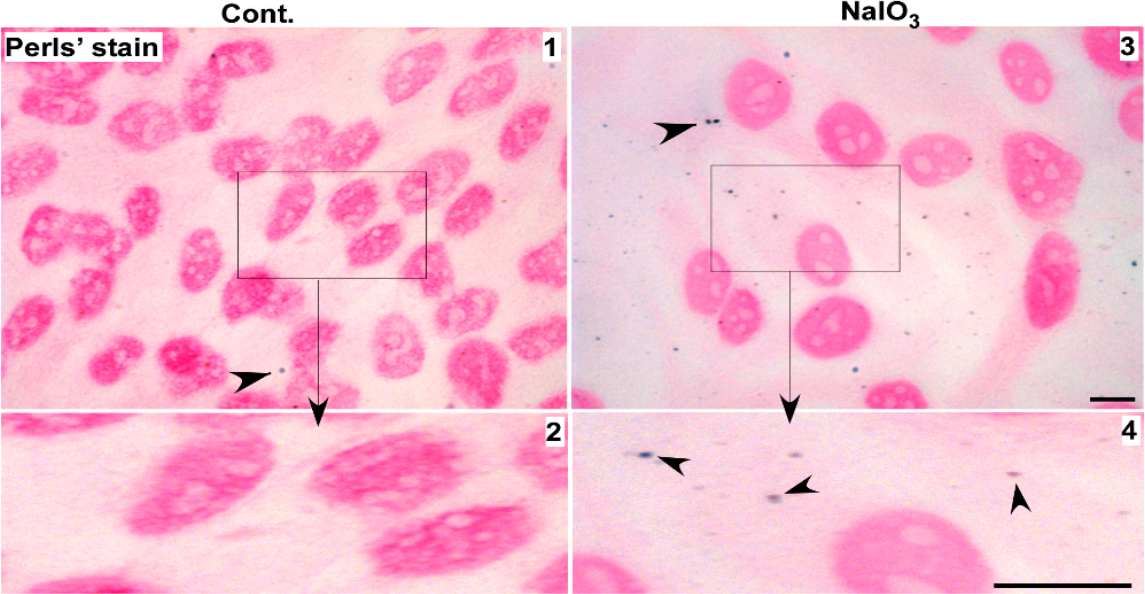

\section{B C57BL/6 mice}

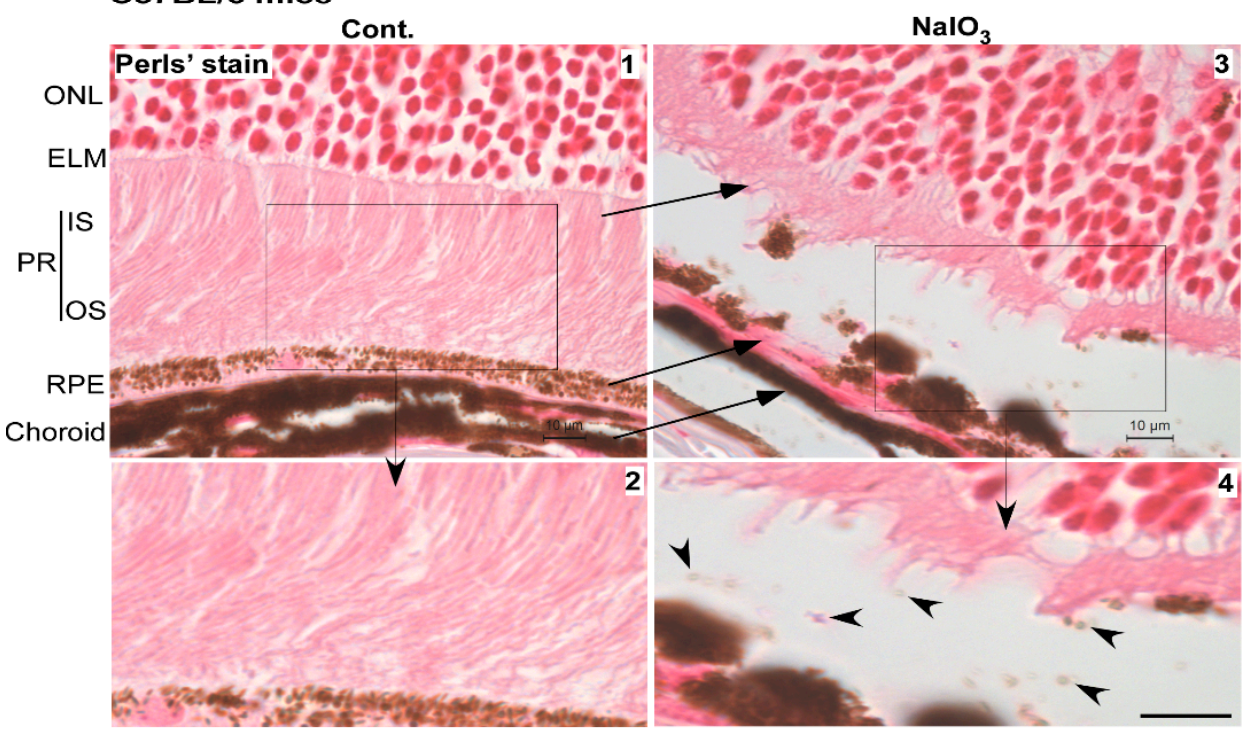

Figure 6. Iron-loaded vesicles are released in the extracellular milieu by $\mathrm{NaIO}_{3}$ treatment. (A) Staining with Perls' reagent showed several blue dots intracellularly and extracellularly in $\mathrm{NaIO}_{3}$-treated ARPE-19 cells (panel 3, arrowhead). Scale bar: $10 \mu \mathrm{m}$. Boxed area is enlarged in panel 4. Scale bar: $10 \mu \mathrm{m}$. A rare blue dot was also noted in control cells (panel 1, arrowhead). Boxed area is enlarged in panel 2. Scale bar: $10 \mu \mathrm{m}$. (B) Perls' reaction of retinal sections from $\mathrm{NaIO}_{3}$-treated mice showed a positive reaction in the space between RPE and PR cells (panel 3, arrowhead), better visualized in the enlarged boxed area (panel 4, arrowheads). Scale bar for panel 3: $10 \mu \mathrm{m}$. Scale bar for panel 4: $10 \mu \mathrm{m}$. RPE: retinal pigment epithelium; PR: photoreceptors; OS: outer segment of photoreceptors; IS: inner segment of photoreceptors; ELM: external limiting membrane; ONL: outer nuclear layer.

\section{Conclusions}

We report dysfunction of lysosomes as a significant contributing factor in AMDlike pathology mediated by $\mathrm{NaIO}_{3}$ in cell and mouse models. Decreased synthesis and maturation of cat-D induced by $\mathrm{NaIO}_{3}$ resulted in the accumulation of iron-loaded ferritin in lysosomes, which was released from cells in lysosomal membrane-derived vesicles. In mouse models, RPE and photoreceptor cell layers were disorganized, and the retina showed accumulation of ferritin as in cell models. These results implicate iron in $\mathrm{NaIO}_{3}$ induced experimental models of AMD, and possibly in human AMD as well because $\mathrm{NaIO}_{3}$ reproduces several features of this disorder (Figure 7). 


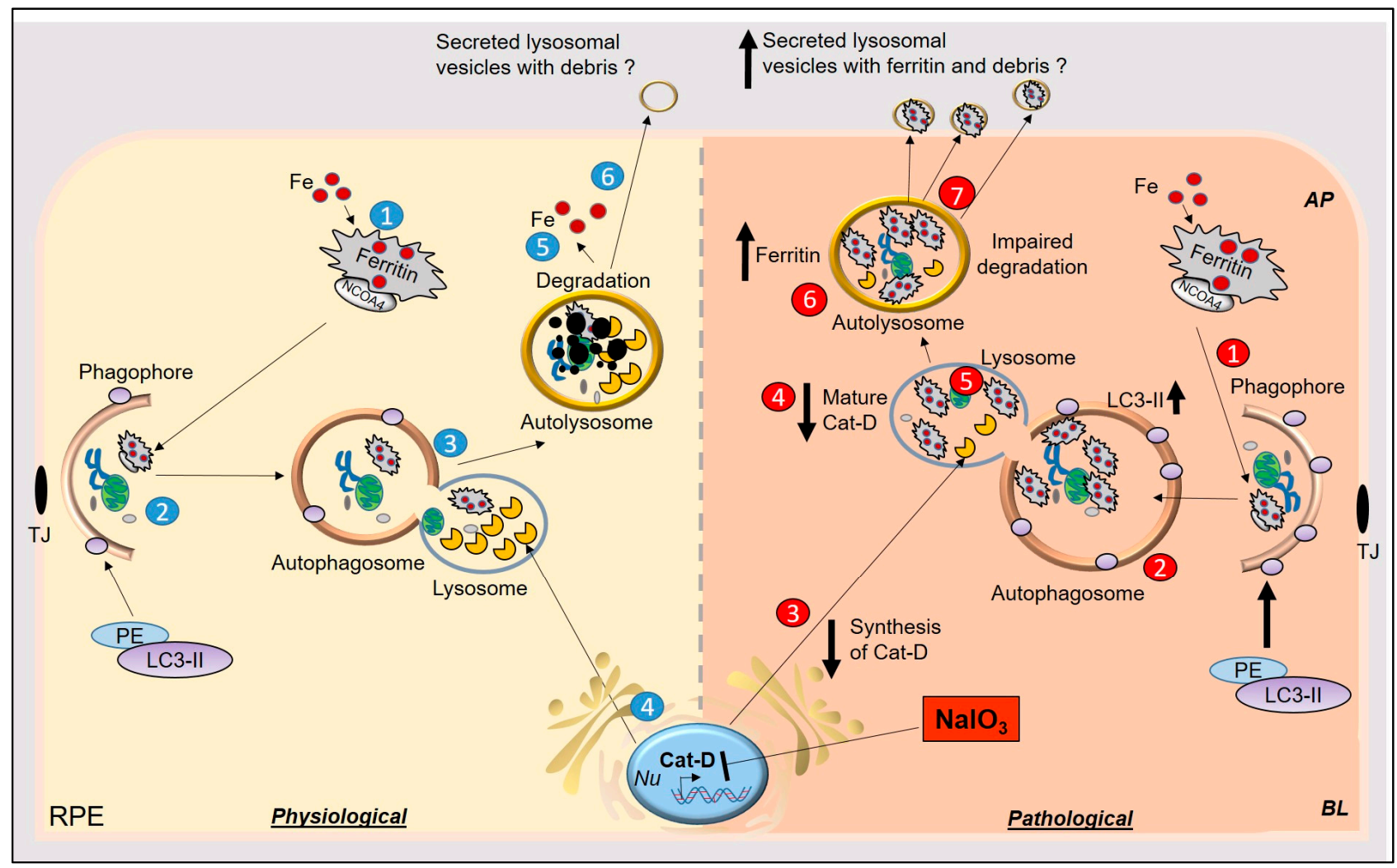

Figure 7. Graphical representation of $\mathrm{NaIO}_{3}$-induced model of AMD in-vitro and in-vivo. Physiological: (1) Iron-loaded ferritin is transported to the phagophore by NCOA4, (2) for degradation with the rest of the cell debris. Levels of LC3II increase with the maturation of phagophore to autophagosome. (3) Autophagosome fuses with lysosomes, (4) where lysosomal enzymes, including cat-D, degrade ferritin and cellular debris. (5) Iron from ferritin is released in the cytosol to be utilized for metabolic purposes. (6) Other debris undergoes autolysis or is secreted via an unconventional lysosomal secretory pathway to the extracellular milieu. Pathological: (1) In $\mathrm{NaIO}_{3}$-induced AMD, iron-loaded ferritin is delivered to the phagophore, (2) which matures into autophagosomes. Levels of LC3II are increased because of accumulation of debris in autophagosomes. (3 and 4) Synthesis and maturation of cat-D are impaired by $\mathrm{NaIO}_{3},(5)$ resulting in the accumulation of iron-loaded ferritin in lysosomes and (6) autolysosomes. (7) Iron-loaded ferritin is secreted in lysosomal vesicles in the extracellular milieu, which is probably internalized by the adjacent photoreceptors, resulting in iron-mediated oxidative stress.

Our observations support previous reports implicating iron in AMD pathogenesis, but suggest a distinct mechanism of retinal iron overload [2,16]. The almost 10-fold increase in iron-loaded ferritin in RPE cells in-vitro and in-vivo is due to dysfunctional lysosomes that are unable to degrade iron-loaded ferritin to release the bound iron [38]. This is supported by no change in the cellular labile iron pool as indicated by minimal change in the expression of major iron modulating proteins such as hepcidin, Fpn, and TfR. Normally, hepcidin is downregulated by increase in intracellular iron, sparing Fpn on the plasma membrane for export of excess iron. TfR, an iron uptake protein, is expected to decrease in an attempt to decrease iron uptake and maintain iron levels within normal limits because iron is an essential cofactor for several vital enzymes [39]. It is likely that iron is sequestered in ferritin and accumulates in autophagosomes and lysosomes. Our observations indicating co-localization of ferritin with LC3II-positive vesicles support this notion and suggest efficient delivery of ferritin by NCOA4 to phagosomes for fusion with lysosomes [40-42]. A small but significant increase in LC3II suggests an increase in autophagosomal activity, though not enough to limit its accumulation. Surprisingly, instead of accumulating in lysosomes, iron-loaded ferritin was released from cells in lysosomal membrane-enclosed vesicles. 
The presence of excess ferritin in the RPE cell layer in-vivo and its dispersion to surrounding retinal layers presents several challenges. Ferritin-rich vesicles are secreted by the non-classical lysosomal secretory pathway [43] and probably gain entry into surrounding cells by ferritin receptors, such as scara- 5 and TfR1 [44,45]. Internalization of ferritin is likely to increase the iron content of these cells and, in addition, other proteins and cellular debris enclosed in these vesicles. This pathway of dissemination of ferritin is of concern not only for AMD, but other ocular disorders associated with ferritin accumulation. The highly secretory nature of RPE cells facilitates this route, which is amplified by oxidative stress [46]. The release of iron-loaded ferritin probably protects these cells from iron-mediated damage but affects the fate of surrounding cells as lysosomal debris and other proteins form sub-RPE deposits typical of AMD [47]. The release of iron-loaded ferritin from RPE cells in lysosomal vesicles has not been reported so far in human AMD. If this is indeed the case and not an artifact of $\mathrm{NaIO}_{3}$ treatment, it would explain the critical role of iron in AMD and help in the development of therapeutic options aimed at preventing retinal iron accumulation.

Our observations suggest that the principal biochemical pathway affected by $\mathrm{NaIO}_{3}$ is decreased synthesis and maturation of cat- $\mathrm{D}$, an aspartic protease responsible for the turnover of phagocytosed debris in RPE cells. Optimal activity of cat-D requires a low $\mathrm{pH}$, and $\mathrm{NaIO}_{3}$ is known to increase lysosomal $\mathrm{pH}$ [48], reducing the activity of several lysosomal enzymes in addition to cat-D. A small but significant reduction in the synthesis of cat-D is also observed, which cannot be explained by reduced $\mathrm{pH}$. It is likely that $\mathrm{NaIO}_{3}$ suppresses the transcription or increases the degradation of its mRNA, resulting in a significant reduction in its mRNA in $\mathrm{NaIO}_{3}$-treated cells. Consistent with these observations, a homozygous knockout mouse model of cat-D develops drusen deposits and retinal dysfunction by 12 months of age, and mice with deletions in cat-D that decrease the level of mature enzyme develop rapid and progressive loss of multiple retinal cell types, underscoring the significance of this enzyme in AMD pathogenesis [49]. However, neither mouse model developed choroidal neovascularization, a feature of wet AMD, indicating that impaired function of cat-D leads to dry AMD. Since cat-D activity is decreased by iron [17], it is likely that accumulation of iron-loaded ferritin and cat-D form a cycle, which, once initiated, feeds itself without additional insults.

In conclusion, this study indicates impaired turnover of iron-loaded ferritin due to impaired lysosomal function as the proximate cause of $\mathrm{NaIO}_{3}$-induced AMD in cell and animal models. Release of these vesicles in the extracellular milieu is likely to cause toxicity to the adjacent photoreceptors, resulting in retinal pathology mimicking AMD. Validation of these findings in human AMD will provide novel therapeutic options (Figure 7).

Supplementary Materials: The following are available online at https:/ / www.mdpi.com/article/ 10.3390 /antiox10081253/s1, Table S1. List of antibodies, Figure S1, Full immunoblots of images presented in the manuscript, Figure S2. Controls for the experiments in Figure 2E and Figure 3 in the manuscript, Figure S3. Controls for the experiment in Figure 5B (panels 5 \& 6) in the manuscript.

Author Contributions: N.S. conceived the study, planned and overlooked experimental design and data interpretation, wrote the manuscript; A.A. performed experiments, analyzed data, wrote the first draft, edited the manuscript; S.C. helped in experiments and edited the manuscript; A.S.W. helped in WB experiments; N.A.R. helped in WB analysis; D.M. helped in RT-qPCR; A.E.K. helped in IHC experiments; E.L. provided critical input. All authors have read and agreed to the published version of the manuscript.

Funding: This work was supported by the National Institutes of Health grant number NS092145 from NINDS. 
Institutional Review Board Statement: All animal experiments were approved by the Institutional Animal Care and Use Committee (Protocol number: 2015-0027) at the School of Medicine, Case Western Reserve University, and were conducted in accordance with the guidelines of the Association for Research in Vision and Ophthalmology on the use of animals in research. Animals were housed in the Association of Assessment and Accreditation of Laboratory Animal Care International (AAALAC)-approved Animal Resource Center (ARC) at Case Western Reserve University School of Medicine. All methods adhered to the ARVO Statement for the Use of Animals in Ophthalmic and Vision Research.

\section{Informed Consent Statement: Not Applicable.}

Data Availability Statement: Data is contained within the article and supplementary files.

Acknowledgments: The authors would like to thank Ramkumar Srinivasagan, Tanu Parmar, and Vipul M. Parmar for their input and Sachin Pillai for assisting with experiments. The authors thank the Visual Sciences Research Center Core Facilities at CWRU (supported by the National Institutes of Health grant P30 EY11373).

Conflicts of Interest: The authors declare no competing interest.

\section{References}

1. Dunaief, J.L. Iron induced oxidative damage as a potential factor in age-related macular degeneration: The Cogan Lecture. Investig. Ophthalmol. Vis. Sci. 2006, 47, 4660-4664. [CrossRef] [PubMed]

2. Hahn, P.; Qian, Y.; Dentchev, T.; Chen, L.; Beard, J.; Harris, Z.L.; Dunaief, J.L. Disruption of ceruloplasmin and hephaestin in mice causes retinal iron overload and retinal degeneration with features of age-related macular degeneration. Proc. Natl. Acad. Sci. USA 2004, 101, 13850-13855. [CrossRef] [PubMed]

3. Biesemeier, A.; Yoeruek, E.; Eibl, O.; Schraermeyer, U. Iron accumulation in Bruch's membrane and melanosomes of donor eyes with age-related macular degeneration. Exp. Eye Res. 2015, 137, 39-49. [CrossRef] [PubMed]

4. Datta, S.; Cano, M.; Ebrahimi, K.; Wang, L.; Handa, J.T. The impact of oxidative stress and inflammation on RPE degeneration in non-neovascular AMD. Prog. Retin. Eye Res. 2017, 60, 201-218. [CrossRef]

5. Hou, X.W.; Wang, Y.; Pan, C.W. Metabolomics in age-related macular degeneration: A systematic review. Investig. Ophthalmol. Vis. Sci. 2020, 61, 13. [CrossRef]

6. Kevany, B.M.; Palczewski, K. Phagocytosis of retinal rod and cone photoreceptors. Physiology 2010, 25, 8-15. [CrossRef] [PubMed]

7. Lim, L.S.; Mitchell, P.; Seddon, J.M.; Holz, F.G.; Wong, T.Y. Age-related macular degeneration. Lancet 2012, 379, 1728-1738. [CrossRef]

8. Rickman, C.B.; Farsiu, S.; Toth, C.A.; Klingeborn, M. Dry age-related macular degeneration: Mechanisms, therapeutic targets, and imaging. Investig. Ophthalmol. Vis. Sci. 2013, 54, ORSF68-ORSF80. [CrossRef]

9. Bird, A. Role of retinal pigment epithelium in age-related macular disease: A systematic review. Br. J. Ophthalmol. 2020. [CrossRef] [PubMed]

10. Strauss, O. The retinal pigment epithelium in visual function. Physiol. Rev. 2005, 85, 845-881. [CrossRef] [PubMed]

11. Kwon, W.; Freeman, S.A. Phagocytosis by the Retinal Pigment Epithelium: Recognition, Resolution, Recycling. Front. Immunol. 2020, 11, 604205. [CrossRef]

12. Ashok, A.; Singh, N.; Chaudhary, S.; Bellamkonda, V.; Kritikos, A.E.; Wise, A.S.; Rana, N.; McDonald, D.; Ayyagari, R. Retinal degeneration and Alzheimer's Disease: An evolving link. Int. J. Mol. Sci. 2020, 21, 7290. [CrossRef] [PubMed]

13. Gnana-Prakasam, J.P.; Tawfik, A.; Romej, M.; Ananth, S.; Martin, P.M.; Smith, S.B.; Ganapathy, V. Iron-mediated retinal degeneration in haemojuvelin-knockout mice. Biochem. J. 2012, 441, 599-608. [CrossRef]

14. Song, D.; Kanu, L.N.; Li, Y.; Kelly, K.L.; Bhuyan, R.K.; Aleman, T.; Morgan, J.I.; Dunaief, J.L. AMD-like retinopathy associated with intravenous iron. Exp. Eye Res. 2016, 151, 122-133. [CrossRef]

15. Hahn, P.; Ying, G.-S.; Beard, J.; Dunaief, J.L. Iron levels in human retina: Sex difference and increase with age. Neuroreport 2006, 17, 1803-1806. [CrossRef]

16. Hadziahmetovic, M.; Dentchev, T.; Song, Y.; Haddad, N.; He, X.; Hahn, P.; Pratico, D.; Wen, R.; Harris, Z.L.; Lambris, J.D.; et al. Ceruloplasmin/hephaestin knockout mice model morphologic and molecular features of AMD. Investig. Ophthalmol. Vis. Sci. 2008, 49, 2728-2736. [CrossRef]

17. Chen, H.; Lukas, T.J.; Du, N.; Suyeoka, G.; Neufeld, A.H. Dysfunction of the retinal pigment epithelium with age: Increased iron decreases phagocytosis and lysosomal activity. Investig. Ophthalmol. Vis. Sci. 2009, 50, 1895-1902. [CrossRef]

18. Regan, C.; De Grip, W.; Daemen, F.; Bonting, S. Degradation of rhodopsin by a lysosomal fraction of retinal pigment epithelium: Biochemical aspects of the visual process. XLI. Exp. Eye Res. 1980, 30, 183-191. [CrossRef]

19. Chowers, G.; Cohen, M.; Marks-Ohana, D.; Stika, S.; Eijzenberg, A.; Banin, E.; Obolensky, A. Course of Sodium Iodate-Induced Retinal Degeneration in Albino and Pigmented Mice. Investig. Ophthalmol. Vis. Sci. 2017, 58, 2239-2249. [CrossRef]

20. Balmer, J.; Zulliger, R.; Roberti, S.; Enzmann, V. Retinal Cell Death Caused by Sodium Iodate Involves Multiple CaspaseDependent and Caspase-Independent Cell-Death Pathways. Int. J. Mol. Sci. 2015, 16, 15086-15103. [CrossRef] 
21. Hanus, J.; Anderson, C.; Sarraf, D.; Ma, J.; Wang, S. Retinal pigment epithelial cell necroptosis in response to sodium iodate. Cell Death Discov. 2016, 2, 16054. [CrossRef]

22. Moriguchi, M.; Nakamura, S.; Inoue, Y.; Nishinaka, A.; Nakamura, M.; Shimazawa, M.; Hara, H. Irreversible Photoreceptors and RPE Cells Damage by Intravenous Sodium Iodate in Mice Is Related to Macrophage Accumulation. Investig. Ophthalmol. Vis. Sci. 2018, 59, 3476-3487. [CrossRef] [PubMed]

23. Wang, J.; Iacovelli, J.; Spencer, C.; Saint-Geniez, M. Direct effect of sodium iodate on neurosensory retina. Investig. Ophthalmol. Vis. Sci. 2014, 55, 1941-1953. [CrossRef]

24. Zhang, X.Y.; Ng, T.K.; Brelen, M.E.; Wu, D.; Wang, J.X.; Chan, K.P.; Yung, J.S.Y.; Cao, D.; Wang, Y.; Zhang, S.; et al. Continuous exposure to non-lethal doses of sodium iodate induces retinal pigment epithelial cell dysfunction. Sci. Rep. 2016, 6, 37279. [CrossRef]

25. Zhao, J.; Kim, H.J.; Sparrow, J.R. Multimodal Fundus Imaging of Sodium Iodate-Treated Mice Informs RPE Susceptibility and Origins of Increased Fundus Autofluorescence. Investig. Ophthalmol. Vis. Sci. 2017, 58, 2152-2159. [CrossRef]

26. Hadziahmetovic, M.; Pajic, M.; Grieco, S.; Song, Y.; Song, D.; Li, Y.; Cwanger, A.; Iacovelli, J.; Chu, S.; Ying, G.-S.; et al. The oral iron chelator deferiprone protects against retinal degeneration induced through diverse mechanisms. Transl. Vis. Sci. Technol. 2012, 1, 2. [CrossRef]

27. Baksi, S.; Singh, N. $\alpha$-Synuclein impairs ferritinophagy in the retinal pigment epithelium: Implications for retinal iron dyshomeostasis in Parkinson's disease. Sci. Rep. 2017, 7, 1-14.

28. Ashok, A.; Chaudhary, S.; McDonald, D.; Kritikos, A.; Bhargava, D.; Singh, N. Local synthesis of hepcidin in the anterior segment of the eye: A novel observation with physiological and pathological implications. Exp. Eye Res. 2020, 190, 107890. [CrossRef]

29. Asthana, A.; Baksi, S.; Ashok, A.; Karmakar, S.; Mammadova, N.; Kokemuller, R.; Greenlee, M.H.; Kong, Q.; Singh, N. Prion protein facilitates retinal iron uptake and is cleaved at the $\beta$-site: Implications for retinal iron homeostasis in prion disorders. Sci. Rep. 2017, 7, 1-14. [CrossRef]

30. Ashok, A.; Kang, M.H.; Wise, A.S.; Pattabiraman, P.; Johnson, W.M.; Lonigro, M.; Ravikumar, R.; Rhee, D.J.; Singh, N. Prion protein modulates endothelial to mesenchyme-like transition in trabecular meshwork cells: Implications for primary open angle glaucoma. Sci. Rep. 2019, 9, 1-15. [CrossRef]

31. Ashok, A.; Singh, N. Prion protein modulates glucose homeostasis by altering intracellular iron. Sci. Rep. 2018, 8, 1-15. [CrossRef]

32. Tripathi, A.K.; Karmakar, S.; Asthana, A.; Ajay, A.; Vilok, D.; Shounak, B.; Neena, S. Transport of non-transferrin bound iron to the brain: Implications for Alzheimer's disease. J. Alzheimers Dis. 2017, 58, 1109-1119. [CrossRef]

33. Gnana-Prakasam, J.P.; Martin, P.M.; Mysona, B.A.; Roon, P.; Smith, S.B.; Ganapathy, V. Hepcidin expression in mouse retina and its regulation via lipopolysaccharide/Toll-like receptor-4 pathway independent of Hfe. Biochem. J. 2008, 411, 79-88. [CrossRef] [PubMed]

34. Fujimaki, M.; Furuya, N.; Saiki, S.; Amo, T.; Imamichi, Y.; Hattori, N. Iron supply via NCOA4-mediated ferritin degradation maintains mitochondrial functions. Mol. Cell Biol. 2019, 39. [CrossRef]

35. Runwal, G.; Stamatakou, E.; Siddiqi, F.H.; Puri, C.; Zhu, Y.; Rubinsztein, D.C. LC3-positive structures are prominent in autophagydeficient cells. Sci. Rep. 2019, 9, 1-14. [CrossRef]

36. Yadati, T.; Houben, T.; Bitorina, A.; Shiri-Sverdlov, R. The ins and outs of cathepsins: Physiological function and role in disease management. Cells 2020, 9, 1679. [CrossRef]

37. Zaidi, N.; Maurer, A.; Nieke, S.; Kalbacher, H. Cathepsin D: A cellular roadmap. Biochem. Biophys. Res. Commun. 2008, 376, 5-9. [CrossRef] [PubMed]

38. Zhang, Y.; Mikhael, M.; Xu, D.; Li, Y.; Soe-Lin, S.; Ning, B.; Li, W.; Nie, G.; Zhao, Y.; Ponka, P. Lysosomal proteolysis is the primary degradation pathway for cytosolic ferritin and cytosolic ferritin degradation is necessary for iron exit. Antioxid. Redox Signal. 2010, 13, 999-1009. [CrossRef]

39. Ganz, T. Systemic iron homeostasis. Physiol. Rev. 2013, 93, 1721-1741. [CrossRef]

40. Bellelli, R.; Federico, G.; Matte, A.; Colecchia, D.; Iolascon, A.; Chiariello, M.; Santoro, M.; De Franceschi, L.; Carlomagno, F. NCOA4 deficiency impairs systemic iron homeostasis. Cell Rep. 2016, 14, 411-421. [CrossRef] [PubMed]

41. Masaldan, S.; Clatworthy, S.A.S.; Gamell, C.; Meggyesy, P.M.; Rigopoulos, A.-T.; Haupt, S.; Haupt, Y.; Denoyer, D.; Adlard, P.A.; Bush, A.; et al. Iron accumulation in senescent cells is coupled with impaired ferritinophagy and inhibition of ferroptosis. Redox Biol. 2018, 14, 100-115. [CrossRef] [PubMed]

42. Nai, A.; Lidonnici, M.R.; Federico, G.; Pettinato, M.; Olivari, V.; Carrillo, F.; Crich, S.G.; Ferrari, G.; Camaschella, C.; Silvestri, L.; et al. NCOA4-mediated ferritinophagy in macrophages is crucial to sustain erythropoiesis in mice. Haematologica 2021, 106, 795-805. [CrossRef] [PubMed]

43. Truman-Rosentsvit, M.; Berenbaum, D.; Spektor, L.; Cohen, L.A.; Belizowsky-Moshe, S.; Lifshitz, L.; Marianna, T.-R.; Li, W.; Kesselman, E.; Abutbul-Ionita, I.; et al. Ferritin is secreted via 2 distinct nonclassical vesicular pathways. Blood 2018, 131, 342-352. [CrossRef] [PubMed]

44. Chiou, B.; Connor, J.R. Emerging and dynamic biomedical uses of ferritin. Pharmaceuticals 2018, 11, 124. [CrossRef]

45. Mendes-Jorge, L.; Ramos, D.; Valença, A.; López-Luppo, M.; Pires, V.M.R.; Catita, J.; Nacher, V.; Navarro, M.; Carretero, A.; Rodriguez-Baeza, A.; et al. L-ferritin binding to scara5: A new iron traffic pathway potentially implicated in retinopathy. PLoS ONE 2014, 9, e106974. [CrossRef] [PubMed] 
46. Atienzar-Aroca, S.; Serrano-Heras, G.; Freire Valls, A.; de Almodovar, C.R.; Muriach, M.; Barcia, J.M.; Garcia-Verdugo, J.M.; Romero, F.J.; Sancho-Pelluz, J. Role of retinal pigment epithelium-derived exosomes and autophagy in new blood vessel formation. J. Cell Mol. Med. 2018, 22, 5244-5256. [CrossRef]

47. Klingeborn, M.; Dismuke, W.M.; Skiba, N.P.; Kelly, U.; Stamer, W.D.; Bowes Rickman, C. Directional Exosome Proteomes Reflect Polarity-Specific Functions in Retinal Pigmented Epithelium Monolayers. Sci. Rep. 2017, 7, 4901. [CrossRef]

48. Lin, Y.-C.; Horng, L.-Y.; Sung, H.-C.; Wu, R.-T. Sodium iodate disrupted the mitochondrial-lysosomal axis in cultured retinal pigment epithelial cells. J. Ocul. Pharmacol. Ther. 2018, 34, 500-511. [CrossRef]

49. Bassal, M.; Liu, J.; Jankowiak, W.; Saftig, P.; Bartsch, U. Rapid and progressive loss of multiple retinal cell types in cathepsin D-deficient mice-An animal model of CLN10 disease. Cells 2021, 10, 696. [CrossRef] 